\title{
Cenlestato
}

\section{Planejamento de marketing para periódicos científicos de acesso aberto}

\author{
Jorge Moisés Kroll do Prado \\ Doutor; Universidade do Estado de Santa Catarina, Florianópolis, SC, Brasil; \\ jorge.exlibris@gmail.com \\ Adilson Luiz Pinto \\ Doutor; Universidade Federal de Santa Catarina, Florianópolis, SC, Brasil; \\ adilson.pinto@ufsc.br
}

\begin{abstract}
Resumo: Descreve as etapas de planejamento de marketing para editores responsáveis por periódicos científicos em acesso aberto, a partir da literatura científica do campo da Administração, onde se consolidou a evolução do marketing desde o início do século XX. Assume uma metodologia de pesquisa descritiva e bibliográfica, com característica qualitativa, sendo um estudo teórico. Verificou-se que o periódico científico precisa ser assumido como um produto e entender que a ciência em acesso aberto, mesmo sem relações de compra e troca, deve ser entendida como um mercado. As etapas que contemplam este planejamento iniciam com a análise do mercado científico, seguido pela compreensão do comportamento de autores, leitores e avaliadores; o desenvolvimento estratégico e o branding do periódico e a comunicação de marketing, onde se apresenta a promoção e a avaliação do planejamento. Por fim, delineiam-se as etapas para um plano de marketing como forma de nortear as atividades e dar insumos para o editor em seu trabalho. É necessário que a execução de marketing seja de maneira planejada e que o editor ultrapasse o limiar da promoção do periódico como um sinônimo de marketing.
\end{abstract}

Palavras-chave: Comunicação científica. Marketing. Periódicos científicos. Acesso aberto.

\section{Introdução}

Em se tratando de ciência, o marketing é um campo do conhecimento muito recente. Teve suas primeiras incursões teóricas no início do Século XX, em um contexto marcado pela produção em massa e vendas com enfoque no esvaziamento de estoques de fábricas ao invés da satisfação do consumidor. Naquela época, pouco se sabia, teoricamente, se marketing era uma nova filosofia, arte, processo, ciência ou técnica dentro da Administração. Esse pano 
de fundo permeia por quase quatro décadas a relação entre teoria e prática, entre o mercado de trabalho envolto pelas grandes empresas e a representatividade de grandes universidades.

Foi somente a partir da década de 1970 que se começou a pensar, ainda dentro da academia, em um marketing mais social, focado em produtos e serviços que não estivessem atrelados somente às relações de compra e venda. Dois foram os segmentos iniciais que receberam esta perspectiva: os museus e as organizações não governamentais (ONGs). A partir disso, percebeu-se que o marketing poderia estar presente em qualquer instituição, marca e até mesmo pessoa física.

Com os periódicos científicos não deixou de ser diferente. Enquanto grandes oligopólios de editoras comerciais possuem departamentos especializados em marketing, com equipe bastante capacitada e multidisciplinar, com os periódicos fora desse contexto a relação é um pouco diferente. Motivado principalmente pelo uso das mídias sociais e pelo discurso sempre premente da divulgação científica para a sociedade em geral, o marketing para editores dessas fontes de informação limitou-se ao uso dessas ferramentas meramente para divulgar novos fascículos e demais novidades. Ou seja, um enfoque dedicado somente à promoção.

O que buscamos apresentar neste artigo, enquanto um estudo teórico, são as etapas necessárias para um planejamento efetivo de marketing por editores de periódicos científicos que estejam em acesso aberto e fora da realidade dos grandes conglomerados científicos. Para isso, a partir de uma pesquisa qualitativa e descritiva, primeiro evidenciamos a dinâmica da comunicação científica e, logo em seguida, apresentamos os conceitos e a evolução do marketing.

\section{Comunicação e periódicos científicos}

$\mathrm{O}$ ato de comunicar é o envio de uma mensagem partindo de um emissor até um receptor. A partir disso, temos o acréscimo de outros fatores como linguagem, canais de mensagem, ambiente, ferramentas e, em seguida, de maneira ainda 
mais detalhada, os aspectos sociais, econômicos, políticos e técnicos. Para a ciência, a comunicação tem um papel preponderante, alinhada com o desenvolvimento das mídias e da própria sociedade em que se insere.

A comunicação científica pode ser entendida como um processo que se inicia com a pesquisa propriamente, seguida de algumas publicações preliminares e por fim, a pesquisa concluída. Lievrouw (1992) identifica que ela possui três fases, sendo: a concepção (quando pesquisadores aprofundam problemas de pesquisa a partir do que já foi publicado e em conversas entre os pares); em seguida, a documentação dessas primeiras descobertas e reflexões (seja a partir de canais formais, como livros e periódicos, ou dos informais, em aulas, eventos, colégios invisíveis); e, por fim, a popularização, quando a ciência alcança o grande público.

Embora tenha sido na Grécia Antiga, com a fala e a escrita como principais artifícios para discussão de questões filosóficas, ambientado no espaço chamado de Academia, que surgiram os primeiros indícios da comunicação científica, somente no Século XVII é que tivemos sua formalização (MEADOWS, 1999). Dois séculos antes, com a influência de academias e sociedades científicas, necessitadas de métodos ágeis e padronizados em disseminar suas descobertas, encontram com o auxílio da imprensa a oportunidade de lançarem os primeiros periódicos de que se tem história.

Em 1660, surge a Royal Society of London for Improving Natural Knowledge, em um contexto em que se predominava a troca de cartas entre os cientistas e os associados da sociedade para comunicar e divulgar seus trabalhos. O interesse em torno dessas publicações, bem como o crescimento do número de destinatários, destaca a atuação de dois secretários: o alemão Henry Oldenburg e o francês Denis de Sallo (ZIMAN 1979; MEADOWS, 1999).

Em janeiro de 1665, De Sallo publicou o primeiro número do Le Journal des Sçavans, trazendo artigos em formato de notícias, redigidos por jornalistas que monitoravam e disseminavam o desenvolvimento das atividades dos cientistas. Dois meses depois, Oldenburg tornou público o Philosophical Transactions, em que o conteúdo era de natureza científica. Mesmo distintas, 
ambas as publicações já eram permeadas por interesses políticos e econômicos, com grande responsabilidade para os secretários que se dedicavam a elas e que passaram a adotar a experiência e apoio de outros associados, como um conselho editorial (ANDRADE, 2014). Esses esforços demonstram a importância dada pelas sociedades científicas da época em comunicar a produção científica.

Anos mais tarde, com a crescente demanda de publicações e a colaboração tecnológica, os periódicos científicos fortaleceram o seu protagonismo como uma das principais, senão a principal, fontes de informação do meio acadêmico. O acesso aberto possui reconhecida participação de destaque nesse fortalecimento, visto que contribui para a democratização da informação científica em todas as suas etapas, da produção à leitura.

A partir de uma iniciativa de pesquisadores da área da Computação, que desenvolveram um sistema simples de compartilhamento de arquivos via diretórios FTP ou HTTP, temos o embrião do acesso aberto (BARRUECO; KRICHEL, 1999). Outro marco importante, oriundo da Física, é a criação, em 1991, do arXiv, um servidor de preprints existente até hoje.

Inúmeras sociedades científicas, universidades e até mesmo pesquisadores renomados tomaram a frente na criação de manifestos, declarações e políticas em prol do acesso aberto. Rios, Lucas e Amorim (2019), ao analisarem as principais iniciativas, apontaram que elas também trouxeram inovações para o movimento, relacionadas ao formato de acesso, depósito, preservação, arquivamento e estrutura, tanto das fontes de informação como dos próprios arquivos dos artigos publicados. Entre os manifestos que merecem ser mencionados estão: Declaração de San José (1998) ${ }^{1}$, Convenção de Santa Fé $(1999)^{2}$, Declaração de Havana $(2001)^{3}$, Declaração de Budapeste (2002) ${ }^{4}$, Declaração de Bethesda (2003) ${ }^{5}$, Declaração de Berlim (2003) ${ }^{6}$ e a Declaração de Haia (2014) ${ }^{7}$ (COSTA; LEITE, 2016; RIOS; LUCAS; AMORIM, 2019; SILVA; ALCARÁ, 2008).

Para amplificar ainda mais o acesso aos periódicos científicos e aproveitando a potencialidade da internet e das mídias sociais, a ciência passa também a circular em ambientes como Twitter, Facebook, ResearchGate e 
outros pautados por uma web social. Junto a isso, novos critérios para indexação passam a contemplar os chamados "planos de marketing" como forma de induzir o trabalho de editores que ainda não passaram a adotar esses ambientes. Essas duas características de contexto tornam ainda mais recorrentes os termos "marketing" e "divulgação" no discurso dos atores da comunicação científica.

\section{Conceito e evolução de marketing}

Se comparado com outros campos, o Marketing é uma área de estudo e de prática bastante recente, tendo suas primeiras menções no início do Século XX. Transitando ainda pelos resquícios da pós Revolução Industrial, as empresas inseriam seus produtos no mercado obedecendo à sistemática de compra em massa, pouco percebendo e avaliando a necessidade da clientela. A concorrência era baixa, portanto, o ato de vender era relativamente simples e bastante lucrativo.

Quando a população começa a agregar valor naquilo que consome e faz com que se torne necessário um engajamento entre cliente e empresa, configurase um mercado mais competitivo, onde já não basta mais produzir em larga escala (BARTELS, 1976). É dentro deste panorama que, aos poucos, tem-se o Fundamento de Marketing, ora interpretado pelos administradores e pesquisadores da época como ciência, ora como arte, técnica, método ou até mesmo filosofia de trabalho.

A influência de outros campos e profissões dentro das estratégias de Marketing também amplia suas possibilidades. A área se enriquece com a inserção de economistas, psicólogos, sociólogos, designers e neurocientistas nos grandes departamentos de marketing das empresas, principalmente a partir dos anos 1950 (SHETH, 1967). O foco e o desafio da época foi entender o comportamento do consumidor não somente voltado para o consumo, mas, inclusive, de maneira irracional (KATONA, 1953), a influência de outras pessoas (KATZ; LAZARSFELD, 1953) e a estrutura familiar (FESTINGER, 1957). Wilkie e Moore (2003) apresentam quatro eras para entender a evolução do Marketing. 
Nas duas primeiras décadas (1900 a 1920) tem-se a chamada fundamentação do marketing, ou seja, um período marcado pelo surgimento dos primeiros cursos sobre o tema, em que o foco do mercado estava na distribuição de produtos. Tudo que fosse relacionado a produto e a bens de consumo, era de interesse tanto dos pesquisadores como das empresas neste período, portanto, foram criados os sistemas de classificação de produtos (RHOADES, 1927; ASPINWALL, 1958) e as funções de marketing (finanças, transporte, vendas, entre outras) para efetivar da melhor maneira possível as transações (WELD, 1917; VANDERBLUE, 1921). É dessa primeira era que vem a influência para, trinta anos depois, a criação do composto de marketing, comumente conhecido como os 4 Ps do marketing, que objetiva desenvolver uma estratégia simples com a elucidação do preço, praça, produto e promoção (MCGARRY, 1950).

A segunda era é chamada de formalização do campo, referente ao período de 1920 a 1950 (WILKIE; MOORE, 2003). Surgem os primeiros eventos, periódicos e entidades dedicadas a dar base teórica para marketing. Muitos intelectuais, neste período, estudaram teorias econômicas para realizar análises de problemas críticos, tanto do campo como do mercado (BARAKAT; LARA: GOSLING, 2011) e outros passaram a construir uma visão sistêmica de todo o processo localizado em mercados muito heterogêneos (ALDERSON, $1954 ; 1965)$.

De 1950 a 1980 apresenta-se a terceira era, compreendida por mudanças de paradigma (WILKIE; MOORE, 2003), sendo a principal delas a mudança de visão do produto e mercado para o consumidor. Aspectos relacionados a comportamento de consumo, escolha de produtos, bem-estar e satisfação são estudados com bastante afinco tanto por pressão de um mercado cada vez mais competitivo, como da academia, que antecipava as necessidades de evolução teórica do campo (ANDREASEN, 1977; CAPLOVITZ, 1963). As ponderações quanto ao público e o impacto das atividades de marketing na sociedade começam a ser evidenciadas também neste período.

Por fim, Wilkie e Moore (2003) destacam que a última era, a partir dos anos 1980, tem por base uma intensificação das mudanças. Há um grande esforço, por parte dos teóricos, em publicar cada vez mais sobre os fenômenos 
apresentados em anos anteriores, como forma de fortalecer o campo. Por parte do mercado, há uma preocupação voltada ao relacionamento.

Cada vez mais se consolidando enquanto campo científico e recebendo grande destaque nas empresas, outros tipos de negócios passam a se dedicar a estudá-lo. Os primeiros foram as organizações não governamentais (ONGs) e os museus que não tinham por finalidade o lucro (KOTLER; KOTLER; KOTLER, 2008; KOTLER; ROBERTO; LEE, 2002). A proposta era justamente utilizar as técnicas de marketing para alcançar seus objetivos, bem como suas missões e entregar valor ao público (agora não mais entendido somente como cliente ou consumidor) a partir de seus produtos e/ou serviços.

Com a ascensão da internet e suas variadas tecnologias de informação e comunicação, o marketing torna-se ainda mais popular e acessível, sendo compreendido de maneira mista como um processo econômico, mas também social. Uma vez que o intuito das organizações passa a ser o de construir e fortalecer relacionamentos, as ferramentas da web 2.0 assumem fundamental importância, já que com elas o internauta deixa de ser um mero navegador e torna-se um criador de conteúdo. O chamado marketing digital, portanto, vem com a proposta de criar, produzir e distribuir conteúdo relevante para seu público-alvo (PULIZZI, 2014).

Dentre os segmentos que começaram a adotar o marketing também está o da comunicação científica. Grandes complexos editoriais internacionais, fora da filosofia e da prática do acesso aberto, possuem departamentos próprios para estudar seus clientes e assim entregar a melhor experiência com seus respectivos periódicos científicos, que vão desde a submissão de um artigo até o relacionamento com o autor publicado. Já no contexto mais comum do acesso aberto, o panorama é bastante diferente: com equipes menores (muitas vezes o editor assumindo várias tarefas), recursos mais escassos (sejam financeiros ou técnicos), a tarefa de marketing, quando raramente realizada, se confunde com a de divulgação (de chamadas para submissões, de publicação de um novo número, de mudanças em suas políticas editoriais, entre outros). 


\section{Metodologia}

Seguimos uma característica qualitativa, buscando apresentar descrições detalhadas sobre os conceitos principais da pesquisa, que são: comunicação e periódicos científicos e marketing. Por este viés, visamos entender todo o fenômeno estudado, ao invés de somente se deter aos resultados.

Em virtude desta necessidade de compreensões teóricas, outra característica da pesquisa é a de ser descritiva, nos levando a contextualizar o processo de marketing na perspectiva dos periódicos científicos em acesso aberto a partir de revisão de literatura. Há aqui uma aproximação entre a literatura científica da área da Administração, onde nasce e se desenvolve o termo, para que se teçam contribuições para o trabalho do editor científico que almeja planejar o trabalho de marketing de seu periódico. Sua natureza teórica é desenvolvida com autores clássicos da área, justamente para oferecer uma contribuição interdisciplinar à Ciência da Informação, em detrimento de autores mais contemporâneos que acabam seguindo uma linha mais instrumental.

E, por fim, com estas características qualitativa e descritiva, visando a construção da plataforma teórica de nosso estudo, atribuímo-nos da pesquisa bibliográfica (MARTINS; TEÓPHILO, 2009). Tivemos em vista “[...] reconstruir teoria, conceitos, ideias, ideologias, polêmicas [para] aprimorar fundamentos teóricos [...]" (DEMO, 2012, p. 22), visto que há uma limitação na literatura sobre comunicação científica em entender o processo de marketing como um conjunto de ações dedicadas, unicamente, à promoção de um produto ou serviço científico, aqui, no caso, o periódico.

\section{Marketing de periódicos científicos em acesso aberto}

Entender o periódico científico como um produto é fundamental para seu desenvolvimento de trabalho com marketing, pois ele atende demandas informacionais de uma determinada comunidade (consumidores), sendo elaborado e administrado por especialistas (produtores). Além disso, se compreendermos que o acesso aberto também pode ser caracterizado como um mercado, dinamizado por outros tipos de capitais que não o monetário 
(simbólico e científico, por exemplo), a execução das etapas que envolvem o marketing também será facilitada.

Em pesquisa bibliográfica na literatura especializada sobre planejamento de marketing, os autores trazem diferentes abordagens, mas muitas delas possuem pontos macro em comum com diversas tarefas: pesquisa de mercado (identificação de público-alvo, análise de concorrência, demandas não atendidas), desenvolvimento de produto (branding, comunicação, posicionamento de mercado, promoção) e avaliação de produto (métricas, readequação de mercado e/ou público-alvo) (VAZ, 2011; KOTLER; KELLER, 2012; YANAZE, 2011). É a partir dos pontos macro que exploramos e ampliamos a possibilidade de aplicação com periódicos científicos de acesso aberto, para que editores e suas equipes editoriais possam desenvolver um planejamento de marketing completo.

\subsection{Análise do mercado científico}

O conceito de mercado deixa de estar atrelado às relações de troca estabelecidas monetariamente a partir do Século XX, quando o próprio conceito de marketing passa a considerar mais relevante o relacionamento que busca criar com o consumidor. Isso também se fortalece com empresas, sem finalidades lucrativas, que passam a atuar de maneira mais estratégica, buscando entender o espaço onde se inserem. Com a transição ou inserção de muitas empresas em ambiente digital, referir-se a mercado também deixa de ter relação com espaços físicos.

$\mathrm{Na}$ comunicação científica, influenciada e rapidamente ampliada pela internet, tornou-se relativamente simples publicar um periódico científico no sentido operacional. Os custos com impressão e veiculação de exemplares deixam de existir e plataformas especializadas em fluxos editoriais potencializam cada vez mais o surgimento dessas fontes de informação, muitas vezes de maneira gratuita.

Tendo mais periódicos científicos disponíveis para a comunidade, mais importante é que o editor adote medidas estratégicas para que garanta sua visibilidade, atraia novos autores e leitores, esteja bem indexado, tenha boas 
métricas, mas, acima de tudo, que sirva como um canal de informação atualizado, fidedigno e atrativo para o campo em que atua. Assim, com um mercado que vai ficando cada vez mais competitivo, é fundamental que se tenha conhecimento de sua dinâmica e encontre as principais lacunas que o periódico possa vir a preencher.

Dentro do marketing, a análise de mercado é primeira etapa, que tem por objetivo mapear o ambiente em que se situa para a proposição ou readequação de um novo produto, que neste caso é o periódico científico (PRADO, 2019). Esta análise inicia-se pela segmentação, em que se agrupam potenciais consumidores, com características e demandas semelhantes dentro do campo científico. Portanto, um editor da Sociologia, por exemplo, pode ramificar subáreas ou temáticas que o periódico pode atender, desde que tenha interesse e demanda da comunidade científica.

Há várias formas de segmentar um mercado, mas Dias (2003) indica como principais a partir da demografia, geograficamente, pelo contexto socioeconômico, por grau de uso ou de maneira psicográfica. Esta segmentação será refletida no foco e escopo do periódico. Podemos mencionar como exemplo a revista Scientometrics, que é especializada em estudos métricos da informação, publicando artigos com metodologias e análises centradas em grandes volumes de dados e apresentados de maneira bastante visual.

As características da sociedade científica, campo, instituição ou programa de pós-graduação também colaboram com a etapa de segmentação, pois os próprios já possuem seus interesses, especialidades, áreas e linhas de pesquisa. Inclusive as apropriações metodológicas, correntes teóricas e linhas de pensamento também são determinantes. Esses elementos com viés para as dinâmicas sociais geralmente já são de conhecimento do próprio editor que convive com elas.

A segmentação pode ser delimitada também por detalhes técnicos, como publicar artigos de autores com titulação de doutorado, estar indexado em bases de grande prestígio, publicar em mais de um idioma e/ou formato, entre outros. Nesse caso, o processo se enriquece com pesquisa de mercado por meio de 
entrevistas, questionários e testes, justamente por colher diretamente as opiniões de autores, avaliadores e leitores reais e potenciais.

No quadro 1 indicamos os principais tipos de pesquisas de mercado que o editor de um periódico científico pode utilizar:

Quadro 1 - Tipos de pesquisa de mercado alinhadas aos periódicos científicos em acesso aberto

\begin{tabular}{|l|l|}
\hline \multicolumn{1}{|c|}{ DEFINIÇÃo } & \multicolumn{1}{c|}{ CARACTERIZAÇÃo } \\
\hline Satisfação do cliente & $\begin{array}{l}\text { Refere-se à pesquisa realizada já com os usuários cadastrados } \\
\text { na plataforma do periódico. Pode ser feita separadamente, } \\
\text { entre autores, leitores e avaliadores, para maior nível de } \\
\text { detalhamento. Outra possibilidade é realizar com autores que } \\
\text { passaram pelo fluxo editorial e tiveram o artigo publicado, } \\
\text { com a finalidade de descobrir os pontos fortes e fracos do } \\
\text { processo. }\end{array}$ \\
\hline Pesquisa de hábitos & $\begin{array}{l}\text { Direcionada para entender navegabilidade no site do } \\
\text { periódico, preferências de leitura, formas de acessar (desktop, } \\
\text { mobile), periodicidade do acesso (se há frequência ou } \\
\text { somente com o lançamento de um artigo/fascículo novo). }\end{array}$ \\
\hline Imagem de marca & $\begin{array}{l}\text { Visa descobrir o que a comunidade científica, em que se } \\
\text { insere o periódico, lembra do periódico, desde seus aspectos } \\
\text { físicos (diagramação, layout, navegabilidade, plataforma } \\
\text { utilizada) até agilidade no fluxo editorial e políticas adotadas } \\
\text { (se usa taxas de submissão, se é íntegra, se está atenta às } \\
\text { tendências da comunicação científica). }\end{array}$ \\
\hline $\begin{array}{l}\text { Pesquisa com equipe } \\
\text { editorial }\end{array}$ & $\begin{array}{l}\text { Mais do que compreender os anseios e comportamentos do } \\
\text { público externo ao periódico, também é necessário ouvir os } \\
\text { atores envolvidos com os bastidores: comitê editorial, } \\
\text { tradutores, revisores, avaliadores etc. Este feedback é } \\
\text { importante para mudanças mais drásticas que porventura o } \\
\text { periódico precise passar. }\end{array}$ \\
\hline
\end{tabular}

Fonte: Adaptado de Schermann (2019).

As pesquisas necessitam de certa periodicidade, com a finalidade de acompanhar a evolução editorial do trabalho e as reações da comunidade científica. Com uma boa análise de mercado, o editor terá as principais informações estratégicas para a criação ou melhoramento de seu periódico. 


\subsection{Comportamento do cliente científico: autores, avaliadores e leitores}

O papel do cliente recebeu grande enfoque no campo de marketing a partir da década de 1960, com a escola de pensamento dedicada a estudar o seu comportamento. Àquela época, o propósito da empresa era somente o de vender. Foi somente com a expansão da internet e das mídias sociais que se passou a considerar a criação de um relacionamento como mais importante.

$\mathrm{Na}$ comunicação científica em acesso aberto a perspectiva é diferenciada. Pela perspectiva de Bourdieu (2004; 2013), os clientes são retratados pelos autores, os avaliadores e os leitores, com interesses distintos permeados por outros tipos de capitais (simbólico, científico e social).

Os autores podem ser entendidos como os principais clientes para os editores já que sem eles, não há artigos. Eles são as forças propulsoras para a produção científica. Por um lado, pressionados a tornar públicas suas pesquisas, dentro de um sistema em que são recompensados mais pela quantidade que pela qualidade de suas publicações, os autores estabelecem como principal alvo periódicos que estejam bem posicionados dentro de seu campo de conhecimento, tenham um processo editorial relativamente ágil, acompanhem tendências básicas da comunicação científica e que possuam boas métricas (seja no âmbito nacional, como o Qualis, como no internacional, como fator de impacto, índice $\mathrm{H}$ e outras).

Dessa forma, para que seja atrativo ao autor, o trabalho do editor e de sua equipe editorial costuma ser norteado por critérios de qualidade estipulados por indexadores de periódicos, mas muito raramente pelo trabalho de marketing que realiza. Esses mesmos indexadores, quando mencionam marketing em seus documentos para ingresso em suas bases, se pautam única e exclusivamente na promoção, indicando que o periódico esteja em mídias sociais de âmbito geral (como Twitter, Facebook e Instagram) e segmentadas (como ResearchGate e Academia.Edu), desmerecendo todas as demais etapas do processo de marketing.

Em seguida, há os leitores que, muitas vezes, também são autores. Eles costumam acompanhar o periódico em situações como: 
- Quando estão interessados em se tornar autores no mesmo, por isso, verificam a qualidade dos artigos publicados, as abordagens metodológicas e teóricas comumente adotadas;

- Se o periódico é referência dentro de seu campo de conhecimento;

- Quando atraídos por estratégias de divulgação (lançamento de um novo número, chamada aberta para fluxo corrente ou um dossiê especial).

Como são raros os trabalhos de propaganda de periódicos científicos em acesso aberto consistentes e planejados a longo prazo, bem como práticas para a fidelização de leitores, muitas vezes o comportamento do leitor parte dele mesmo, não sendo induzido a "consumir" o periódico.

E, por fim, há o avaliador, cliente fundamental para o editor. Por se tratar de uma atividade não-remunerada, é necessário manter uma boa base de avaliadores, comprometidos com prazos e a qualidade dos pareceres. Formas não monetárias que recompensem a atividade do avaliador precisam ser cada vez mais suscitadas dentro da comunicação científica, para que os mesmos se sintam motivados, a começar pelo reconhecimento que precisa ser dado por agências de fomento e universidades a este papel na análise de seus currículos para progressão de carreira e avaliação de projetos.

Cada vez mais, as empresas buscam construir uma relação de confiança com o consumidor ao ponto de se desenvolver técnicas para um marketing de relacionamento. Na comunicação científica, é de fundamental importância que o relacionamento com os clientes também seja cada vez mais fortalecido e mais explorado por parte dos editores. No Quadro 2, são indicadas algumas estratégias básicas de marketing para este intuito.

Quadro 2 - Estratégias de marketing de relacionamento para os clientes da comunicação científica

\begin{tabular}{|l|l|}
\hline \multicolumn{1}{|c|}{ CLIENTE } & \multicolumn{1}{c|}{ ESTRATÉGIAS } \\
\hline AUTOR & $\begin{array}{l}\text { - Emissão de boletins de métricas (downloads, acessos, citação) a } \\
\text { respeito de seu artigo } \\
\text { - Posicionamento de visibilidade do artigo frente a outros dentro }\end{array}$ \\
\hline
\end{tabular}




\begin{tabular}{|l|l|}
\hline & $\begin{array}{l}\text { do periódico ou da temática em que o artigo se insere } \\
\text { - Peças publicitárias com o próprio autor a respeito de seu artigo, } \\
\text { veiculadas em formato de vídeo ou ilustração } \\
\text { - Postura clara e aberta com o autor durante todo o fluxo editorial }\end{array}$ \\
\hline LEITOR & $\begin{array}{l}\text { - Divulgação de novos fascículos publicados } \\
\text { - Lançamento de dossiês temáticos } \\
\text { - Publicações não-científicas, veiculadas em mídias sociais (como } \\
\text { um blog), mostrando os bastidores e curiosidades sobre o } \\
\text { periódico coma com } \\
\text { - Ferramentas de leitura e discussão compartilhada, seja com } \\
\text { outros leitores, seja com os autores }\end{array}$ \\
\hline AVALIADOR & $\begin{array}{l}\text { - Emissão de certificado/declaração sobre a avaliação emitida } \\
\text { - Dicas para a qualificação da avaliação }\end{array}$ \\
\hline
\end{tabular}

Fonte: Adaptado de Prado (2019).

Diferente do mercado tradicional de compra e venda, no de periódicos científicos de acesso aberto um ator/cliente transita entre perfis diferentes, ora assumindo o papel de autor, ora o de avaliador, por exemplo. Logo, as propostas de relacionamento apresentadas no Quadro 2 devem ser vistas como um conjunto que fortaleça este tipo de marketing. Quanto mais dados relativos a este relacionamento, melhor será o trabalho de gestão do editor e suas tomadas de decisão frente ao periódico.

\subsection{Desenvolvimento estratégico e branding do periódico}

O desenvolvimento estratégico do periódico é um trabalho contínuo, que se retroalimenta a partir da interação com seu público-alvo, da visibilidade alcançada e dos parâmetros de qualidade recebidos, principalmente com o ingresso em indexadores. Infelizmente, muitos periódicos são criados por motivação do próprio produtivismo acadêmico ou de certo status que ele pode vir a garantir para o editor que o comanda. Esse fator crítico contribui para a saturação do mercado do campo científico, em que o autor se depara com vários espaços para submeter seu trabalho, mas com focos e escopos muito semelhantes e poucos critérios temáticos.

Embora essa subseção possa vir a trazer a impressão de que deveria ser a primeira, ela aqui foi colocada propositalmente como terceira, pois, justamente 
depois de entender as peculiaridades de interação comunicacional científica e de como seus atores-clientes se comportam, é que o editor priorizará os elementos que aqui queremos discutir.

Pela visão do marketing, todo produto ou serviço possui um ciclo de vida com quatro etapas: introdução, crescimento, maturidade e declínio (SANDHUSEN, 1998; LIMEIRA, 2003). Saber quando cada uma começa e termina pode colaborar com a sua própria melhoria, desenvolvimento ou, até mesmo, seu encerramento. De toda forma, estas fases não podem ser compreendidas como estanques, ou seja, elas podem se sobrepor, se readequar, conforme o dinamismo social do contexto em que estão inseridos. O que se apresenta a seguir é o ideal preconizado pela literatura do marketing, cabendo ao editor do periódico considerar e avaliar a fase em que se encontra.

A fase de introdução de um periódico dentro de um campo científico refere-se a ele já pronto, divulgado para sua comunidade científica e já publicando artigos. Essa fase pode perdurar por um bom período de tempo, pois até que os potenciais autores creditem confiança, utilizem-no como fonte de consulta e o mesmo passe a figurar com bons critérios de qualidade (estar indexado, ter bons índices de citação, possuir alguns elementos técnicos básicos), passarão alguns meses.

$\mathrm{Na}$ fase de crescimento, o periódico começa a se consolidar no campo em que está inserido. Já está com bom número de artigos no fluxo editorial, tem uma equipe de avaliadores trabalhando com prazos efetivamente, os artigos publicados começam a receber suas primeiras citações. Geralmente nessa fase se realiza a maioria das mudanças de gestão do periódico, como publicar em diferentes formatos de leitura, mais fascículos publicados por ano ou até mesmo a adoção de sistemas que contribuem com a aceleração da comunicação científica, como Online First e publicação contínua.

O periódico chega na fase de maturidade quando se depara com um mercado científico mais concorrido, em que surgem mais opções para os autores publicarem seus trabalhos ou, então, em que há a necessidade em aumentar os números de citação. Aqui, estratégias de promoção do periódico passam a ser adotadas com mais afinco, como o uso de mídias sociais, envio de e-mails para 
público-alvo e potencial, além de outras estratégias (técnicas ou não) que sirvam como um chamariz.

E, por último, há a etapa de declínio. No mercado capitalista tradicional, de trocas e vendas, essa etapa diz respeito ao momento em que o produto ou serviço encontra a obsolescência, em que outro da concorrência passa a entregar a mesma funcionalidade de maneira melhor. Já no mercado científico, é comum esse declínio acontecer por problemas operacionais com o editor (relacionados à saúde, assumir outra função e não ter outra pessoa que possa conduzir o periódico em seu lugar), com o próprio periódico (no sentido técnico, quanto à manutenção do software em que está hospedado; mas também de qualidade, ao não alcançar novos patamares), acúmulo de submissões no fluxo editorial, encerramento das atividades do grupo em que está inserido (como um programa de pós-graduação ou uma sociedade científica).

Dessa forma, para as quatro fases supracitadas, o editor precisa se atribuir de estratégias e de técnicas para a gestão e o desenvolvimento de seu periódico, estando atento tanto às tendências da comunicação científica como um todo, quanto às práticas realizadas por seu campo.

O processo dedicado ao desenvolvimento da marca de um produto ou serviço é chamado de branding. Entende-se por marca como "um conjunto de imagens - em geral, um nome, um logotipo e um slogan - que distingue a oferta do produto ou serviço de uma empresa das ofertas de seus concorrentes (KOTLER; KARTAJAYA; SETIAWAN, 2017, p. 65). Esse conjunto, além de assumir representatividade gráfica, é responsável também pela mensagem em torno de seus princípios, valores e práticas, que é transmitida ao público desejado e a forma que é lembrada pelo público (seja tanto pelos elementos gráficos como por sua postura).

O branding é construído a partir dos elementos anteriores: análise de mercado e os aspectos comportamentais. Ambos dão insumos para que o editor posicione seu periódico de maneira mais assertiva. Um periódico pode ter mensagens e ideias atreladas a si a partir de sua identidade visual (formatos publicados de um artigo, software de gestão, diagramação, apresentação das capas), de aspectos simbólicos (status do editor, importância para o campo), de 
índices qualificadores (números de download, métricas como fator de impacto e Qualis, taxas de citação) e de gestão (qualidade da avaliação, respeito aos prazos, agilidade, ética, acesso aberto, periodicidade, entre outros). Dessa forma, o branding, embora sua aplicação seja indicada no nascimento do periódico, é um processo que pode ser constante, conforme períodos de tempo determinados (a cada cinco anos, em média).

Aaker (2012) e Prado (2019) afirmam que o branding pode ser desenvolvido a partir de três passos. O primeiro deles é identificar as associações que devem ser lembradas pela comunidade científica. Tais associações devem ser expressas em palavras-chaves atreladas a memórias, percepções, conceitos e lembranças (exemplos: ágil, ético, eficiente, inovador, esteticamente elegante, qualificado, simples, comunicativo). O ideal é que esse primeiro passo seja feito em formato de brainstorming, para que seja elencado o maior número possível de associações.

A partir desse agrupamento, o editor deve realizar um filtro de modo a se estabelecer somente as palavras-chave mais importantes e reais para o seu trabalho com o periódico. Aaker (2012) indica quatro critérios que ajudam nessa seleção: i) repercussão: como o periódico será visto na comunidade científica; ii) diferenciação: o que ele entrega de diferente dos demais dentro de seu campo do conhecimento, seja no sentido visual, seja em suas práticas; iii) paridade: indicadores de qualidade, como estar presente em certos indexadores cooperam com a visibilidade da marca do periódico, portanto, não basta ao editor atuar somente com repercussão e diferenciação, mas também acompanhar essas exigências; e iv) cultura e estratégia: a forma como o editor se comunica com sua comunidade, tendo processos transparentes, apoiando o desenvolvimento do movimento do acesso aberto, sendo ético, evitando conflitos de interesses e outras ações que reflitam cultural e estrategicamente o periódico científico.

E, por fim, a partir da delimitação das principais associações que o editor deseja que a comunidade tenha com o seu trabalho, é que se desenvolverão as tarefas relacionadas aos aspectos visuais (fontes cores, slogans), à linguagem, à delimitação de foco e escopo, à adoção ou não de práticas ágeis de fluxo 
editorial (Online First, Ahead of Print, preprints, publicação contínua), uso de mídias sociais (como será feito, em quais delas, com qual periodicidade e que tipo de conteúdo). O branding é um processo rotineiro e essencial para qualquer marca, devendo ser revisto constantemente.

\subsection{Comunicação de marketing do periódico}

De todos os elementos que contemplam o marketing, o da promoção é o que mais atrai os entusiastas da temática, já que seus resultados (mesmo que de pouco valor) são rapidamente aparentes. Ela é somente um dos objetivos almejados pela comunicação de marketing, ou seja, a etapa que seleciona os canais com os quais o editor comunicará sobre seu periódico. Limeira (2003) afirma que a promoção é um conjunto de ações integradas para fixar determinado produto ou serviço na mente do consumidor, de modo a fortalecer sua marca.

O editor pode elencar alguns objetivos próprios para alcançar com a comunicação, como por exemplo, aumentar sua lembrança entre os autores que irão submeter um novo artigo, estimular mudanças de atitudes na comunicação científica (como a avaliação aberta), estar presente também fora de seu campo do conhecimento, ter presença digital nas mídias sociais, entre outras. A análise de mercado, ao destacar oportunidades no início do planejamento do periódico, pode colaborar com esta determinação de objetivos para a comunicação de marketing.

Em seguida, o editor precisa identificar o público-alvo que deseja alcançar com cada objetivo. Destaca-se que esse público costuma mudar conforme o objetivo, mesmo que o mercado da comunicação científica possa parecer sempre o mesmo, dentro das particularidades de seu campo. Limeira (2003) nos lembra que este público da comunicação é maior que do produto em si, ou seja, o editor não deverá se limitar a comunicar somente com os pesquisadores que estejam cadastrados no sistema de gestão de seu periódico.

Com objetivos e públicos definidos, é chegado o momento de identificar as melhores ferramentas, técnicas e atividades para efetivar a comunicação. Podemos apresentar duas de usufruto dos editores. A primeira delas é a 
propaganda, que tem sido a de maior destaque, já que possui formas próprias de alcançar o público, destaca os benefícios do periódico, transmite sua mensagem e fortalece sua marca. A segunda são as relações públicas, que podem engajar e atrair novos leitores e autores, transparecendo eticamente o fluxo editorial, transmitindo confiança e sendo ágil na comunicação com seu público.

A seleção dos meios de comunicação que serão utilizados pelo editor é a última fase do planejamento de comunicação de marketing. Nos últimos anos, as mídias sociais têm sido as mais utilizadas pelo seu viés democrático, aberto e propício para a conversação. Inclusive, alguns documentos de indexação de periódicos colocam como exigência em seus critérios que haja presença nas mídias sociais, o que é importante, mas se equivocam quando equiparam esta presença (meramente pela criação de postagens) como sendo todo o processo de marketing.

A definição de quais canais de comunicação serão utilizados deve partir de uma análise do editor com sua equipe editorial. Deve-se considerar a dinâmica particular de seu campo do conhecimento, mas também como a ciência em acesso aberto vem se comportando dentro de determinados espaços.

\section{Plano de marketing}

Trabalhar com marketing envolve planejamento e entender todo o processo, que possui fases que se interligam e se retroalimentam. É muito mais do que promover o periódico científico e estar presente nas mídias sociais, é atuar de maneira estratégica e competitiva. Para colaborar com essa função, o plano de marketing é um documento essencial para que o editor consiga visualizar todas as etapas, acompanhá-las e realinhá-las, sempre que necessário. Na literatura especializada, há diferentes modelos, para diferentes tipos de segmentos econômicos, bem como produtos e serviços. Os itens recomendados para estarem em um plano de marketing de periódico científico em acesso aberto são pautados a partir de alguns autores (POLIZEI, 2010; KOTLER; KELLER, 2012; GIRTON, 2018; AMBRÓSIO, 2007; JONES, 2003), mas com discussão adaptada às particularidades da comunicação científica. 
1) Apresentação: elemento em que se destacam informações como: histórico do periódico, foco e escopo, equipe editorial, mas, acima de tudo, as que explicam a motivação de elaboração do plano de marketing e sua estrutura.

2) Descrição do mercado: situar o periódico dentro do campo, destacando dados como: quantos outros periódicos existem, quantos programas de pós-graduação estão alocados no mesmo campo do conhecimento, a periodicidade dos demais periódicos, qual é seu público-alvo (caracterização dos autores reais e potenciais, estratégias de publicação, os formatos adotados para avaliação de submissões), os principais indexadores existentes alinhados com o que almeja o periódico.

3) Objetivos do periódico: deve-se apresentar quais aqueles que estão em conformidade com a atuação geral do periódico, não somente de marketing (estes estarão na fase de comunicação de marketing dentro do plano). Isto é, se o editor deseja que seu periódico seja o mais renomado dentro de seu campo, ele se encaixaria aqui como um objetivo (o que levaria a alinhar todas as estratégias de marketing com este objetivo).

4) Estratégias: delimitar todas as estratégias, de cada objetivo, que deverão ser executadas. Para distinguir, podemos utilizar como exemplo o intuito do editor fortalecer a presença digital de seu periódico, logo, ele poderá colocar como estratégias: melhorar o site, adotar mídias sociais, desenvolver um plano de postagens nas mídias sociais, ampliar o posicionamento em buscadores da internet.

5) Implementação: detalhar todas as tarefas que precisam ser realizadas para cada estratégia. O ideal é que o editor elenque como um plano de trabalho, atribuindo prazos, funções, ferramentas e formas de monitorar a performance de cada estratégia de acordo com o objetivo do plano. É comum que quando se redija esta etapa, também seja necessário revisitar outras seções do documento, readequando objetivos quando necessário.

6) Avaliação: é comum que esta etapa seja esquecida, mas é fundamental que o editor tenha métricas que forneçam dados para a sua tomada de decisão. Quando há objetivos quantitativos, como alavancar o número de 
seguidores em uma mídia social do periódico, é necessário que tenha um acompanhamento dos números desse engajamento e que os mesmos estejam em relatórios para análise futura. Com isso, o editor poderá melhorar o seu plano de marketing e estipular novos prazos para sua atualização.

Com esses seis elementos delineados, o editor conseguirá ter um marketing executado de maneira planejada, podendo, dentro de um determinado período, reavaliar objetivos e estratégias para que a visibilidade e utilidade de seu periódico cresçam cada vez mais.

\section{Considerações finais}

A internet e, principalmente, as mídias sociais trouxeram à maioria dos segmentos econômicos e sociais uma visibilidade inadvertida. A forma com que ambas possibilitam diferentes identidades, alcance, produção e consumo de informação fez com que tais segmentos revissem a entrega de seus serviços e produtos. Dentro deste contexto, o marketing foi um dos processos que mais ganhou espaço, inclusive com a comunicação científica.

O que buscamos retratar neste artigo foi a reflexão teórica, com vistas às práticas editoriais, da necessidade de executar o marketing de periódicos científicos em acesso aberto de forma planejada, para que, em consequência, o próprio termo se consolide da devida forma. A confusão e limitação teóricas com o termo limitam o trabalho do editor em somente promover o seu periódico, desconsiderando etapas prévias de planejamento. Assim, pontuamos as fases de desenvolvimento de um trabalho com marketing, finalizando com os elementos necessários para um plano.

Tal proposta teórica não finda aqui. É necessário que o debate seja aprofundado com mais publicações que não se limitem à promoção do periódico enquanto sinônimo de marketing, mas que o tema esteja presente em eventos da editoração científica a partir do olhar embrionário da Administração (já que é com ela que nascem as discussões teóricas e práticas para o desenvolvimento do conceito) e que a ciência aberta possa ser compreendida como um mercado. 


\section{REFERÊNCIAS}

AAKER, D. A. Administração estratégica de mercado. Porto Alegre: Bookman, 2012.

ALDERSON, W. Factors governing the development of marketing channels. In: CLEWETT, R. Marketing channels for manufactured products. Homewood, Illinois: Richard D. Irwin, 1954.

ALDERSON, W. Dynamic marketing behaviour: a functionalist theory of marketing. Homewood, Illinois: Richard D. Irwin, 1965.

AMBRÓSIO, V. Plano de marketing: um roteiro para a ação. São Paulo: Prentice Hall, 2007.

ANDRADE, V. T. A. Comunicação científica na sociedade em rede: uma plataforma da ciência aberta para o Brasil. 229f. 2014. Tese (Doutorado em Comunicação) - Programa de Pós-Graduação em Comunicação, Centro de Artes e Comunicação, Universidade Federal de Pernambuco, Recife, 2014.

ANDREASEN, A. R. A taxonomy of consumer satisfaction/dissatisfaction measures. In: HUNT, H. K. (org.). Conceptualization and measurement of consumer satisfaction and dissatisfaction. Cambridge, Massachusetts:

Marketing Science Institute, 1977.

ASPINWALL, L. The characteristics of goods and parallel system theories. In: KELLEY, E. K.; LAZER, W. (orgs.). Managerial Marketing. Homewood, Illinois: Richard D. Irwin Inc., 1958.

BARAKAT, L. L.; LARA; J. E.; GOSLING, M. O surgimento da escola de pensamento do marketing de relacionamento e seus fundamentos. Pretexto, Belo Horizonte, v. 12, n. 3, p. 29-46, jul./set. 2011.

BARRUECO, J. M.; KRICHEL, T. Acceso a prepublicaciones en Economía. RePEc, Oct., 1999.

BARTELS, R. The history of marketing thought. Columbus, OH: Grid, 1976.

BOURDIEU, P. Os usos sociais das ciências: por uma sociologia clínica do campo científico. São Paulo: UNESP, 2004.

BOURDIEU, P. A economia das trocas simbólicas. 7. ed. São Paulo: Perspectiva, 2013.

CAPLOVITZ, D. The poor pay more: consumer practices of low-income families. New York: The Free Press of Glencoe, 1963. 
COSTA, M. P. da; LEITE, F. C. L. Acesso aberto no mundo e na América Latina: uma revisão a partir da Budapest Open Access Initiative.

Transinformação, Campinas, v. 28, n. 1, 2016, p. 33-46.

DEMO, P. Pesquisa e informação qualitativa: aportes metodológicos.

Campinas: Papirus, 2012.

DIAS, S. R. Análise de mercado. In: DIAS, S. R. (org.). Gestão de marketing. São Paulo: Saraiva, 2003.

FESTINGER, L. A theory of cognitive dissonance. New York: Row Peterson and Company, 1957.

GIRTON, C. Creating a marketing plan with a marketing team of one.

Marketing Libraries Journal, v. 2, n. 1, 2018.

JONES, V. Plano de marketing. In: DIAS, S. R. (coord.). Gestão de marketing. São Paulo: Saraiva, 2003.

KATONA, G. C. Rational behavior and economic behavior. Psychological Review, v. 60, Sep. 1953.

KATZ, E.; LAZARSFELD, P. F. Personal influence: the part played by people in the flow of mass communications. New York: The Free Press, 1955.

KOTLER, P.; KARTAJAYA, H.; SETIAWAN, I. Marketing 4.0: do tradicional ao digital. Rio de Janeiro: Sextante, 2017.

KOTLER, N. G.; KOTLER, P.; KOTLER, W. I. Museum marketing and strategy: designing missions, building audiences, generating revenues and resources. New York: John Wiley \& Sons, 2008.

KOTLER, P.; KELLER, K. L. Administração de marketing. 14. ed. São Paulo: Pearson Education do Brasil, 2012.

KOTLER, P.; ROBERTO, N.; LEE, N. R. Social marketing: improving the quality of life. Thousand Oaks: Sage Publishing, 2002.

LIEVROUW, 1. A. Communication, representation and scientific knowledge; a conceptual framework and case study. Knowledge and Policy: The International Journal of Knowledge Transfer and Utilization, New Brundwick, v. 5, n. 1, p. 6-28, Spring 1992.

LIMEIRA, T. M. V. Administração de produtos. In DIAS, S. R. (coord.). Gestão de marketing. São Paulo: Saraiva, 2003.

MARTINS, G. A.; THEÓPHILO, C. R. Metodologia da investigação científica para ciências sociais aplicadas. 2. ed. São Paulo: Atlas, 2009. 
MCGARRY, E. D. Some functions of marketing reconsidered. In: COX, R.; ALDERSON, W. (orgs.). Marketing theory. Chicago: Richard D. Irwin Inc., 1950.

MEADOWS, A. J. A comunicação científica. Brasília, DF: Briquet de Lemos Livros, 1999.

PRADO, J. M. K. do. Evidências teóricas para um marketing da ciência em acesso aberto. 139f. 2019. Tese (Doutorado em Ciência da Informação) Programa de Pós-Graduação em Ciência da Informação, Centro de Ciências da Educação, Universidade Federal de Santa Catarina, Florianópolis, 2019.

POLIZEI, E. Plano de marketing. São Paulo: Cengage Learning, 2010.

PULIZZI, J. Epic content marketing: how to tell a different story, break through clutter, and win more customers by marketing less. Nova York: McGraw Hill, 2014.

RHOADES, E. L. Introductory readings in Marketing. Chicago: A. W. Shaw Company, 1927.

RIOS, F. P.; LUCAS, E. R. O.; AMORIM, I. S. Manifestos do movimento de acesso aberto: Análise de Domínio a partir de periódicos brasileiros. Revista Brasileira de Biblioteconomia e Documentação, São Paulo, v. 15, n. 1, 2019.

SANDHUSEN, R. L. Marketing básico. São Paulo: Saraiva, 1998.

SCHERMANN, D. Pesquisa de mercado: o que é, como fazer e questionários de pesquisa. Opinion Box, Belo Horizonte, 31 jan. 2019. Disponível em: https://blog.opinionbox.com/pesquisa-de-mercado-o-que-e/. Acesso em: 15 maio 2020.

SHETH, J. N. A review of buyer behavior. Management Science, v. 13, Aug. 1967, p. B718-B756.

SILVA, T. E.; ALCARÁ, A. R. Políticas de acesso aberto à informação científica: iniciativas governamentais. In: ENCONTRO NACIONAL DE PESQUISA EM CIÊNCIA DA INFORMAÇÃO, 9., São Paulo, 2008. Anais... São Paulo: USP, 2008.

VANDERBLUE, H. B. The functional approach to the study of Marketing. Journal of Political Economy, v. 29, October 1921, p. 676-683.

VAZ, C. A. Os 8Ps do marketing digital: o guia estratégico de marketing digital. São Paulo: Novatec, 2011. 
ZIMAN, J. M. Conhecimento público. Belo Horizonte: Itatiaia; São Paulo: EDUSP, 1979.

YANAZE, M. H. Gestão de marketing e comunicação: avanços e aplicações. 2. ed. São Paulo: Saraiva, 2011.

WELD, L. D. H. Marketing functions and mercantile organization. American Economic Review, Pittsburgh, v. 7, June 1917, p. 306-318.

WILKIE, W. L.; MOORE, E. S. Scholarly research in marketing: exploring the "4 Eras" of Thought Development. Journal of Public Policy \& Marketing, Washington, v. 22, n. 2, 2003.

\title{
Marketing planning for open access scientific journals
}

\begin{abstract}
It describes the stages of marketing planning for editors responsible for open access scientific journals, mainly from the scientific literature in the field of Administration, where the evolution of marketing has been consolidated since the beginning of the 20th century. The article assumes a descriptive and bibliographic research methodology, with qualitative characteristics, being a theoretical study. It was found that the scientific journal needs to be assumed as product and understand that science in open access, even without buying and exchange relationships, must be understood as a market. The steps that contemplate this planning begin with the analysis of the scientific market, followed by the understanding of the behavior of authors, readers and reviewers; the strategic development and branding of the journal and marketing communication, where the promotion and evaluation of planning is presented. Finally, the steps for a marketing plan are outlined as a way to guide activities and provide inputs for the editor in his work. It is necessary that the execution of marketing be in a planned manner and the editor surpasses the threshold of promoting the journal as a synonym of marketing.
\end{abstract}

Keywords: Scientific communication. Marketing. Scientific journals. Open access.

Recebido: 28/9/2020

Aceito: 19/01/2021

Declaração de Autoria

Concepção e elaboração do estudo: Jorge Moisés Kroll do Prado, Adilson Luiz Pinto

Coleta de dados: Jorge Moisés Kroll do Prado

Análise e interpretação de dados: Jorge Moisés Kroll do Prado

Redação: Jorge Moisés Kroll do Prado

Revisão crítica do manuscrito: Adilson Luiz Pinto 


\section{Como Citar}

PRADP, Jorge Moisés Kroll do; PINTO, Adilson Luiz.Planejamento de marketing para periódicos científicos de acesso aberto. Em Questão, Porto Alegre, v. 27, n. 3, p. 375-400, 2021. Doi: http://dx.doi.org/10.19132/18085245273.375-400

1 Declaración de San José hacia la Biblioteca Virtual en Salud (1998). Disponível em: https://pesquisa.bvsalud.org/portal/resource/pt/lil-231724. Acesso em: 06 maio 2021.

2 The Santa Fe Convention for the Open Archives Initiative (1999). Disponível em: http://www.openarchives.org/sfc/sfc entry.htm. Acesso em: 06 maio 2021.

${ }^{3}$ Declaração de Havana Rumo ao Acesso Equitativo à Informação em Saúde (2001). Disponível em: $\quad$ http://red.bvsalud.org/modelo-bvs/wp-content/uploads/sites/3/2016/05/Declaracao-deHavana-Rumo-ao-Acesso-Equitativo-a-Informacao-em-Saude.pdf. Acesso em: 06 maio 2021.

4 Budapest Open Access Initiative (2002). Disponível em: https://www.budapestopenaccessinitiative.org/read. Acesso em: 06 maio 2021.

5 Bethesda Statement on Open Access Publishing (2003). Disponível em: https://legacy.earlham.edu/ peters/fos/bethesda.htm. Acesso em: 06 maio 2021.

${ }^{6}$ Berlin Declaration on Open Access to Knowledge in the Sciences and Humanities (2003). Disponível em: https://openaccess.mpg.de/Berlin-Declaration. Acesso em: 06 maio 2021.

7 The Hague Declaration (2014). Disponível em: https://libereurope.eu/the-hague-declaration/. Acesso em; 06 maio 2021. 